\title{
Chrome Extension untuk Data Grabber Media Sosial Twitter dengan Metode XPath Selector
}

\author{
Chrome Extension for Twitter Data Grabber using XPath Selector Method
}

\author{
Erinda Resha $\mathrm{A}^{1}$, Antonius Rachmat $\mathrm{C}^{2}$, Yuan Lukito ${ }^{3}$ \\ ${ }^{1,2,3}$ Informatika, Universitas Kristen Duta Wacana \\ E-mail : ${ }^{1}$ erinda.resha@ti.ukdw.ac.id, ${ }^{2}$ anton@ti.ukdw.ac.id, ${ }^{3}$ yuanlukito@ti.ukdw.ac.id
}

\begin{abstract}
Abstrak
Kebutuhan dataset sebagai sumber penelitian untuk analisis oleh data scientist terus meningkat seiring dengan semakin meningkatnya rasa keingintahuan manusia. Misalnya seperti suatu perusahaan ingin mengetahui tanggapan konsumennya tentang produk yang baru saja diluncurkan, sehingga mereka dapat menyusun langkah selanjutnya yang akan diambil oleh perusahaan tersebut. Tentu saja untuk mengetahui hal tersebut, perlu dilakukan analisis terhadap tanggapan konsumen terlebih dahulu. Analisis dilakukan menggunakan sumber data yang dapat ditemukan salah satunya pada sosial media seperti Twitter. Penelitian ini dimaksudkan untuk menyediakan aplikasi yang dapat digunakan menjadi data grabber untuk mengumpulkan data dari media sosial Twitter. Aplikasi data grabber dirancang sebagai Chrome Extension dengan implementasi metode XPath Selector diharapkan dapat mengumpulkan data tanpa terbatasi oleh batasan akses API Twitter. Sebagai gantinya dengan menerapkan metode ini, aplikasi perlu mengakses halaman web Twitter. Pemasangan aplikasi sebagai Chrome Extension memudahkan untuk menjalankan aplikasi sembari mengakses halaman web Twitter pada browser. Aplikasi TweetGrabberERA berhasil dibangun pada penelitian ini sesuai kebutuhan yang diharapkan. Pengujian yang dirancang telah menunjukkan bahwa aplikasi data grabber dengan mengimplementasikan metode XPath Selector berjalan dengan baik dan membuktikan bahwa aplikasi dapat menghasilkan dataset yang untuk keperluan keperluan analisis oleh data scientist.
\end{abstract}

Kata kunci: XPath Selector, Chrome Extension, data grabber, Twitter

\begin{abstract}
The need of datasets as research sources for analysis by data scientists continues to increase along with the increasing of human curiosity. For example, a company wants to know consumers' response about the products that have been launched, so they can arrange the next steps to be taken by the company. To do so, analysis of consumers' response must be done. The analysis can be done using data sources that come from social media such as Twitter. This research is intended to provide an application used as a data grabber to collect data from social media Twitter. This application is designed as a Chrome Extension with implementation of XPath Selector expected to collect data without being limited by Twitter API access restrictions. Instead of applying this method, this application needs to access Twitter web page. As Chrome Extension, it's easy to run while accessing Twitter web pages in the browser. TweetGrabberERA was successfully built in this study. It has shown that data grabber application with implementation of the XPath Selector runs well and proved can produce a dataset for the purposes of analysis by data scientists.
\end{abstract}

Keywords: XPath Selector, Chrome Extension, data grabber, Twitter

\section{PENDAHULUAN}

Media sosial digunakan sebagai media komunikasi dan berbagi informasi secara daring. Media sosial telah menjadi salah satu kebutuhan hidup bagi kaum muda maupun tua sehingga kepopuleran media sosial terus meningkat dari tahun ke tahun. Salah satu media sosial yang masih menjadi tren yaitu Twitter. Twitter merupakan media sosial daring yang cukup populer, hingga saat ini tercatat 330 juta pengguna aktif tiap bulannya [1]. Twitter menampilkan tweet yaitu 
kiriman yang memiliki batas tidak lebih dari 280 karakter [2], membuatnya terlihat sederhana sehingga mudah untuk dibaca. Informasi-informasi yang banyak ditemukan biasanya berupa berita, ilmu pengetahuan, opini, dan masalah personal. Agar dapat memanfaatkan informasi yang ada, perlunya sebuah aplikasi yang dapat membantu mengumpulkan informasi-informasi tersebut dalam suatu bentuk dataset sehingga pengolahan informasi akan menjadi lebih mudah.

Data grabber merupakan salah satu solusi, dimana aplikasi tersebut dapat bekerja untuk mengambil data secara otomatis. Metode yang mudah dijumpai untuk pengambilan data pada Twitter adalah melalui API Twitter seperti yang telah diterapkan pada Tweepy. Tweepy sendiri merupakan sebuah library di Python yang digunakan untuk mengakses API Twitter. Sayangnya untuk mengakses API Twitter, perlu melakukan pengesahan kredensial dimana pengguna akan diminta untuk memasukkan consumer key, consumer secret key, access token key, access token secret key yang hanya didapat melalui izin dari Twitter. Hal tersebut sungguh membatasi pengguna untuk dapat mengumpulkan tweet.

Untuk memudahkan penggunaan aplikasi, browser Chrome saat ini telah dilengkapi dengan add-on yang disebut Chrome Extension. Dengan adanya Chrome Extension pengguna dapat melakukan kustomisasi terhadap browsernya sehingga akan mendapatkan pengalaman baru yang berbeda [3]. Memasang Chrome Extension pada browser Chrome, penggunaan aplikasi sambil mengakses situs web pada browser menjadi lebih sederhana.

Rizaldi dan Arief [4] meneliti tentang perbandingan metode web scraping menggunakan CSS Selector dan XPath Selector. Penelitian ini membahas permasalahan bagaimana kelengkapan data yang diperoleh, penggunaan memori, dan kecepatan waktu yang diperlukan ketika menggunakan XPath Selector dan CSS Selector pada situs berita sebagai metode web scraping menggunakan tools Scrapy. Kesimpulan dari penelitian mereka adalah penggunaan metode XPath Selector menghasilkan artikel yang lebih lengkap dibandingkan dengan menggunakan metode CSS Selector untuk web scraping situs berita walaupun membutuhkan proses lain untuk menghilangkan kode HTML yang tidak diinginkan. Penggunaan memori oleh metode XPath Selector dan CSS Selector tidak memiliki perbedaan yang signifikan bahkan cenderung sama sedangkan pada sisi kecepatan waktu secara umum metode XPath Selector memiliki waktu proses yang lebih cepat daripada menggunakan metode CSS Selector.

Adapun masalah yang akan dihadapi ketika menggunakan metode XPath Selector. Struktur web seperti media sosial Twitter ini akan selalu diperbarui dalam jangka waktu tertentu. Hal tersebut jelas akan menimbulkan kendala ketika menggunakan XPath Selector yang bekerja dengan cara melakukan navigasi pada halaman HTML [5]. Perlunya penyesuaian kembali agar aplikasi tetap berjalan sesuai harapan.

Penelitian ini bertumpu pada penelitian yang dilakukan oleh Rizaldi dan Arief. Penelitian ini akan membuat aplikasi data grabber dalam bentuk add-on pada browser Chrome yang disebut Chrome Extension. Aplikasi dibangun untuk menjadi data grabber media sosial Twitter dengan mengimplementasikan metode XPath Selector.

\section{METODE PENELITIAN}

\subsection{Perancangan Sistem}

Aplikasi Chrome Extension untuk Data Grabber Media Sosial Twitter dengan metode XPath Selector disusun dengan arsitektur seperti pada Gambar 1. Aplikasi yang berupa Chrome Extension mengambil data dari situs media sosial Twitter yang dibangun menggunakan JavaScript. Pengambilan data dilakukan melalui elemen HTML situs media sosial Twitter dengan mencari XPath yang tepat, sehingga tidak memerlukan API dari Twitter. Data yang telah diperoleh selanjutnya akan diolah, disusun, lalu disimpan ke dalam penyimpanan lokal. IndexedDB merupakan database lokal pada browser yang digunakan oleh aplikasi. Dengan adanya AlaSQL, IndexedDB akan lebih mudah diakses karena AlaSQL telah menyediakan library yang memberi kenyamanan akses penuh melalui JavaScript ke database termasuk 
IndexedDB menggunakan query SQL. Data yang telah terkumpul dapat diekspor oleh aplikasi menjadi file dalam bentuk CSV.

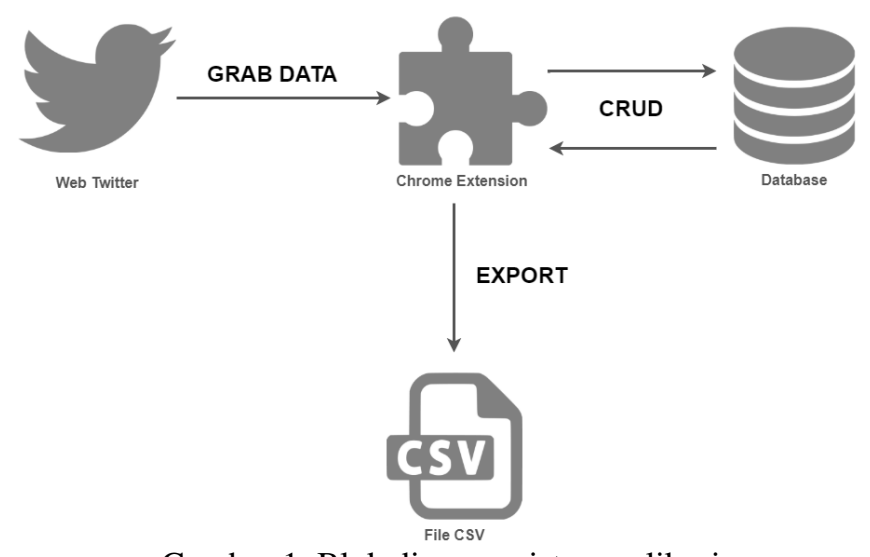

Gambar 1. Blok diagram sistem aplikasi

Pada alur kerja sistem untuk Chrome Extension ini, pengguna diwajibkan untuk mengisi input yang diminta sebelum aplikasi dijalankan. Fitur penjadwalan merupakan fitur opsional untuk digunakan. Flowchart untuk alur aplikasi dijelaskan pada Gambar 2.

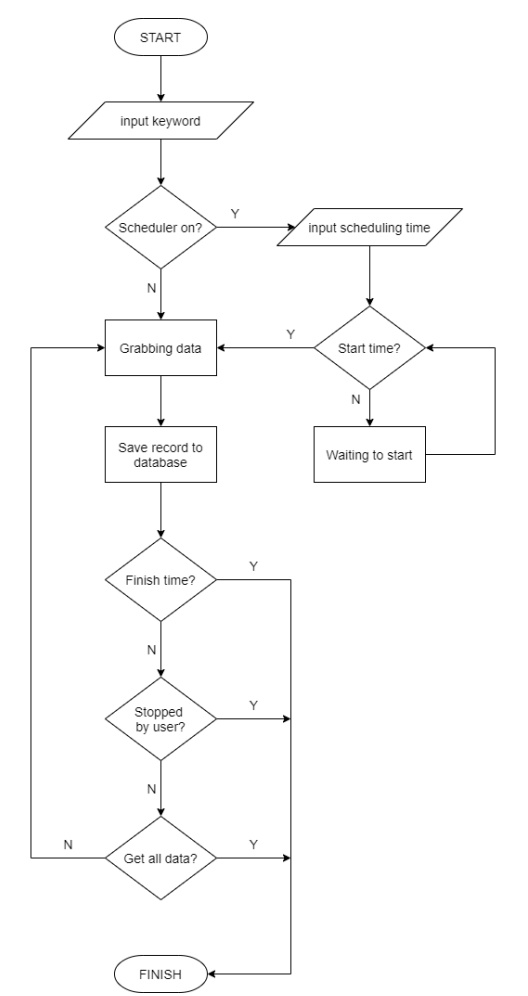

Gambar 2. Flowchart Chrome Extension

Untuk memulai aplikasi, pengguna perlu untuk melakukan beberapa persiapan seperti menginputkan keyword dan memilih ingin menggunakan fitur penjadwalan atau tidak. Jika fitur penjadwalan dinyalakan, maka pengguna harus menginputkan waktu mulai dan selesai. Aplikasi mulai bekerja ketika pengguna telah menekan tombol OK. Aplikasi melakukan pengecekan apakah pengguna menggunakan fitur penjadwalan atau tidak. Jika fitur penjadwalan dijalankan, maka aplikasi akan mulai dan mengakhiri kerja grabbing data sesuai jadwal yang diinputkan. Jika fitur penjadwalan tidak dijalankan, maka aplikasi langsung melakukan grabbing data saat itu juga dan akan berakhir ketika pengguna menekan tombol STOP. 


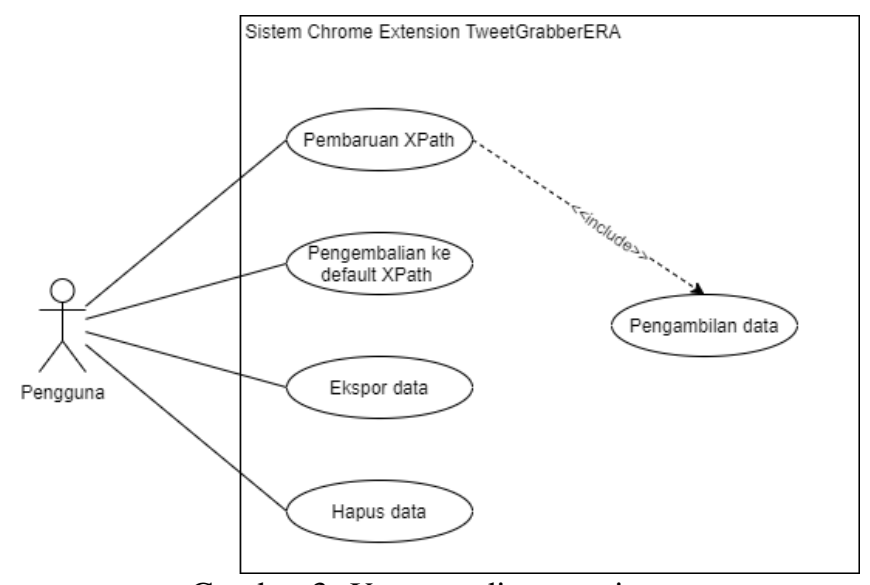

Gambar 3. Use case diagram sistem

Sesuai dengan use case diagram pada Gambar 3 pengguna dapat melakukan beberapa hal seperti memperbarui XPath, mengembalikan XPath ke default XPath, melakukan ekspor data, dan menghapus data. Untuk melakukan pembaruan XPath, pengguna setidaknya harus telah melakukan fitur pengambilan data. Hal ini diperlukan agar aplikasi dapat mendeteksi adanya perubahan pada struktur elemen halaman web Twitter atau tidak.

Rancangan halaman antarmuka aplikasi Chrome Extension terdiri dari 2 bagian, yaitu halaman pop up dan halaman tambahan (additional page). Halaman pop up akan muncul ketika ikon Chrome Extension diklik untuk mengaktifkan aplikasi. Saat Chrome Extension belum berjalan, рор up akan meminta pengguna untuk melakukan setting awal seperti memasukkan keyword, memilih urutan tampilan tweet, dan membuat penjadwalan kerja aplikasi. Selain itu ada halaman setting untuk melakukan pengaturan aplikasi seperti scan XPath elemen web Twitter, mengembalikan tatanan XPath aplikasi ke bentuk awal yaitu Twitter versi rilis 21 April 2020, dan melakukan export, atau delete database. Tampilan halaman pop up, dapat dilihat pada Gambar 4.

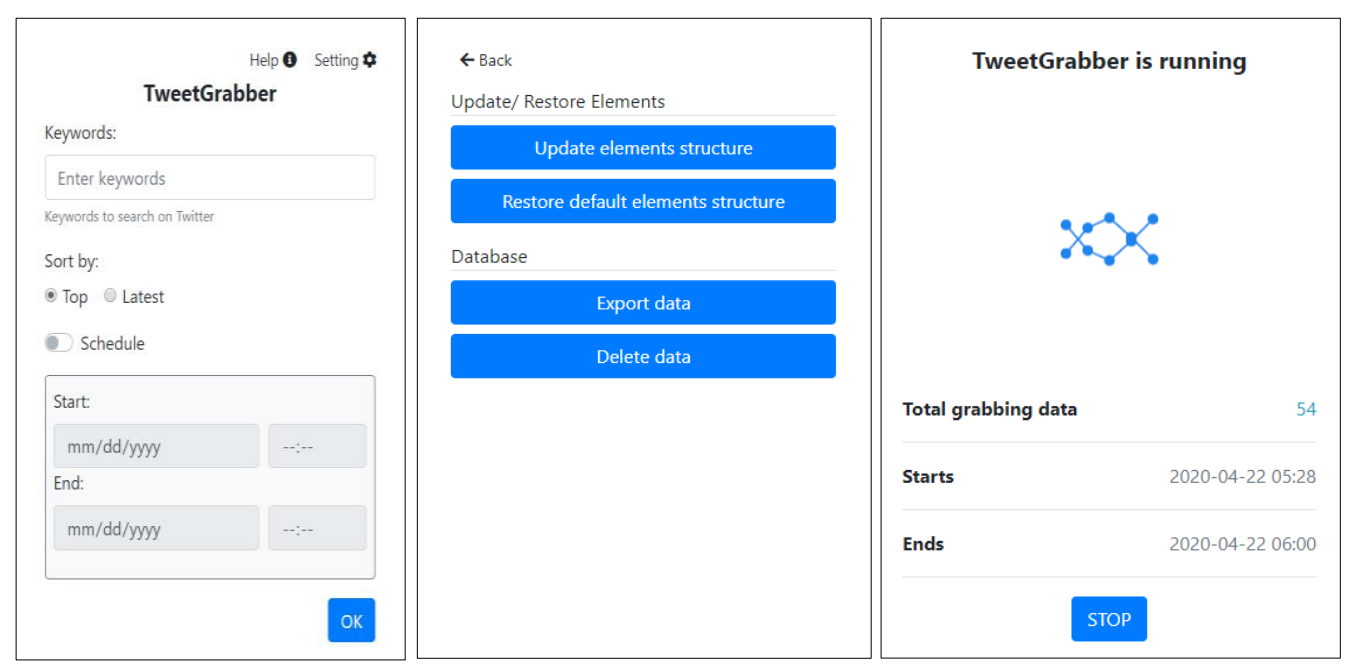

Gambar 4. Halaman pop up menu utama, menu setting, dan pop up ketika aplikasi berjalan

Sebuah halaman yang berisi deskripsi aplikasi, penjelasan cara kerja aplikasi secara garis besar, dan kolom bantuan. Agar nantinya dapat diakses oleh pengguna jika mengalami kesulitan ketika menjalankan aplikasi. Rupa desain tampilan dapat dilihat pada Gambar 5. 


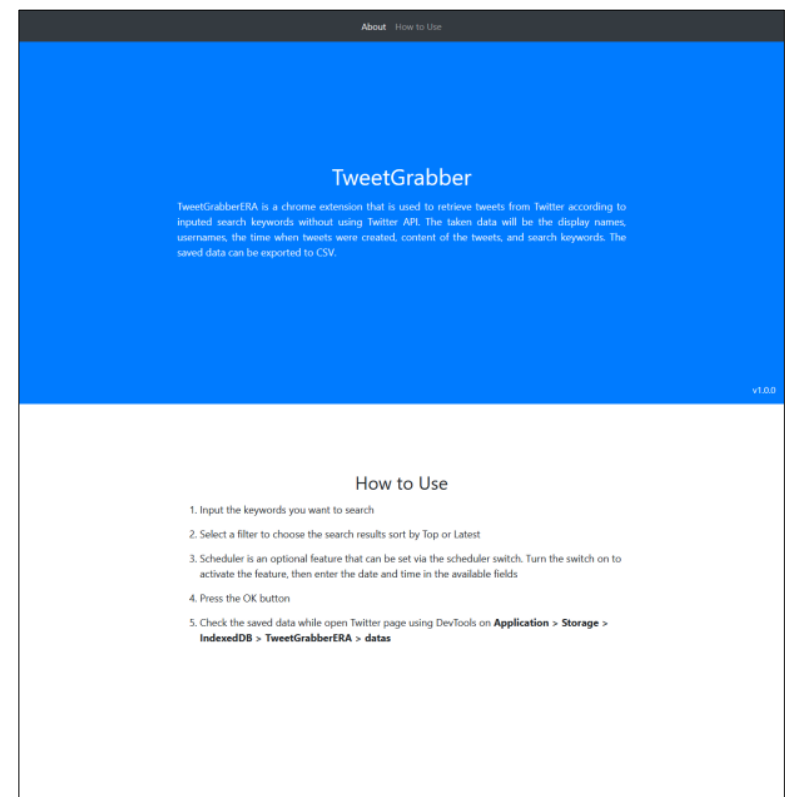

Gambar 5. Halaman tambahan berisi informasi aplikasi

Basis data yang digunakan pada aplikasi Chrome Extension dibuat menggunakan IndexedDB. Aplikasi hanya memiliki satu objectStore bernama datas dengan struktur seperti pada Tabel 1.

Tabel 1 Struktur Tabel Database TweetGrabberERA

\begin{tabular}{|l|l|l|}
\hline \multicolumn{2}{|c|}{ Key } & \multicolumn{2}{c|}{ Talue } & \multicolumn{1}{c|}{ Keterangan } \\
\hline tweet_id & String & id tweet \\
\hline created_at & Date & waktu dan tanggal tweet dibuat \\
\hline name & String & nama akun pembuat tweet \\
\hline username & String & username pembuat tweet \\
\hline text_content & String & isi teks tweet kiriman pengguna \\
\hline keyword & String & kata yang dicari dalam tweet \\
\hline
\end{tabular}

\subsection{Perancangan Pengujian Sistem}

\subsubsection{Pengujian Aplikasi}

Pengujian aplikasi akan berfokus tentang kesesuaian kerja aplikasi dengan rancangan yang telah dibuat. Penulis telah membuat beberapa skenario-skenario kerja seluruh fitur aplikasi untuk melakukan pengujian ini. Pengujian terhadap aplikasi ini dijelaskan melalui Tabel 2.

Aplikasi TweetGrabberERA yang telah diuji selanjutnya akan dibandingkan dengan aplikasi pada penelitian terdahulu, yaitu Automatic Crawling Data in Twitter yang dibangun oleh Sembodo dkk. [6]. Hal ini dilakukan untuk menunjukkan kelebihan dan kekurangan berdasarkan fitur dari aplikasi atau program yang memiliki fungsi yang sama yaitu dapat melakukan pengambilan data pada Twitter.

Tabel 2 Skenario Pengujian

\begin{tabular}{|c|l|l|}
\hline \multicolumn{3}{|c|}{ Fitur Grabbing Data } \\
\hline ID & \multicolumn{1}{|c|}{ Skenario Test } & \multicolumn{1}{c|}{ Expected Results } \\
\hline TGF01001 & Aplikasi meminta pengguna untuk menginputkan keyword & $\begin{array}{l}\text { Muncul peringatan yang meminta pengguna } \\
\text { untuk menginputkan keyword. }\end{array}$ \\
\hline TGF01002 & $\begin{array}{l}\text { Aplikasi mengambil data dari halaman web Twitter yang } \\
\text { melakukan pencarian mengandung keyword "morning” } \\
\text { dengan filter "Top" }\end{array}$ & $\begin{array}{l}\text { Data yang mengandung keyword "morning" } \\
\text { dengan urutan sesuai filter "Top" tersimpan } \\
\text { dalam database dan halaman pop up } \\
\text { menampilkan total seluruh data yang telah } \\
\text { tersimpan dalam database. }\end{array}$ \\
\hline
\end{tabular}




\begin{tabular}{|c|c|c|}
\hline TGF01003 & $\begin{array}{l}\text { Aplikasi mengambil data dari halaman web Twitter yang } \\
\text { melakukan pencarian mengandung keyword "morning" } \\
\text { dengan filter "Latest" }\end{array}$ & $\begin{array}{l}\text { Data yang mengandung keyword "morning" } \\
\text { dengan urutan sesuai filter "Latest" } \\
\text { tersimpan dalam database dan halaman pop } \\
\text { up menampilkan total seluruh data yang } \\
\text { telah tersimpan dalam database. }\end{array}$ \\
\hline TGF01004 & $\begin{array}{l}\text { Aplikasi melakukan scroll pada halaman web Twitter ketika } \\
\text { belum mencapai hasil pencarian paling akhir }\end{array}$ & $\begin{array}{l}\text { Halaman web Twitter melakukan scroll } \\
\text { secara otomatis. }\end{array}$ \\
\hline TGF01005 & $\begin{array}{l}\text { Aplikasi berhenti mengambil data ketika sampai pada hasil } \\
\text { pencarian paling akhir }\end{array}$ & $\begin{array}{l}\text { Aplikasi berhenti bekerja lalu mengeluarkan } \\
\text { pop up bahwa aplikasi telah berhenti karena } \\
\text { telah sampai pada hasil pencarian paling } \\
\text { akhir. }\end{array}$ \\
\hline TGF01006 & $\begin{array}{l}\text { Aplikasi berhenti bekerja ketika hasil pencarian sesuai } \\
\text { keyword "zxcvbnmtgb" dan filter "Top" dari pengguna tidak } \\
\text { ditemukan }\end{array}$ & $\begin{array}{l}\text { Aplikasi berhenti bekerja lalu mengeluarkan } \\
\text { pop up bahwa aplikasi telah berhenti karena } \\
\text { hasil pencarian tidak ditemukan. }\end{array}$ \\
\hline TGF01007 & $\begin{array}{l}\text { Aplikasi berhenti bekerja ketika hasil pencarian tidak muncul } \\
\text { setelah } 1 \text { menit berlalu }\end{array}$ & $\begin{array}{l}\text { Aplikasi berhenti bekerja lalu mengeluarkan } \\
\text { pop up yang meminta pengguna untuk } \\
\text { mengecek koneksi internet. }\end{array}$ \\
\hline TGF01008 & $\begin{array}{l}\text { Aplikasi berhenti bekerja ketika URL halaman pada tab } \\
\text { browser yang digunakan untuk mengambil data diubah }\end{array}$ & $\begin{array}{l}\text { Aplikasi berhenti bekerja lalu mengeluarkan } \\
\text { pop up bahwa aplikasi telah berhenti karena } \\
\text { URL halaman telah diubah. }\end{array}$ \\
\hline TGF01009 & $\begin{array}{l}\text { Aplikasi berhenti bekerja ketika tab browser yang digunakan } \\
\text { untuk mengambil data ditutup }\end{array}$ & Aplikasi berhenti bekerja \\
\hline TGF01010 & $\begin{array}{l}\text { Aplikasi berhenti bekerja ketika jendela browser yang } \\
\text { digunakan untuk mengambil data ditutup }\end{array}$ & Aplikasi berhenti bekerja. \\
\hline TGF01011 & Pengetesan ulang TGF01001 setelah melakukan update XPath & Sama seperti hasil pengetesan TGF01001 \\
\hline TGF01012 & Pengetesan ulang TGF01002 setelah melakukan update XPath & Sama seperti hasil pengetesan TGF01002 \\
\hline TGF01013 & Pengetesan ulang TGF01003 setelah melakukan update XPath & Sama seperti hasil pengetesan TGF01003 \\
\hline TGF01014 & Pengetesan ulang TGF01004 setelah melakukan update XPath & Sama seperti hasil pengetesan TGF01004 \\
\hline TGF01015 & Pengetesan ulang TGF01005 setelah melakukan update XPath & Sama seperti hasil pengetesan TGF01005 \\
\hline TGF01016 & Pengetesan ulang TGF01006 setelah melakukan update XPath & Sama seperti hasil pengetesan TGF01006 \\
\hline TGF01017 & Pengetesan ulang TGF01007 setelah melakukan update XPath & Sama seperti hasil pengetesan TGF01007 \\
\hline TGF01018 & Pengetesan ulang TGF01008 setelah melakukan update XPath & Sama seperti hasil pengetesan TGF01008 \\
\hline TGF01019 & Pengetesan ulang TGF01009 setelah melakukan update XPath & Sama seperti hasil pengetesan TGF01009 \\
\hline TGF01020 & Pengetesan ulang TGF01010 setelah melakukan update XPath & Sama seperti hasil pengetesan TGF01010 \\
\hline \multicolumn{3}{|c|}{ Fitur Penjadwalan } \\
\hline ID & Skenario Test & Expected Results \\
\hline TGF02001 & $\begin{array}{l}\text { Aplikasi berjalan sesuai jadwal yang diinputkan pada kolom } \\
\text { Start }\end{array}$ & $\begin{array}{l}\text { Muncul tanggal dan waktu sesuai input dari } \\
\text { pengguna pada kolom Start di pop up. } \\
\text { Aplikasi mulai bekerja dengan menunjukkan } \\
\text { gambar loading bergerak dan jumlah data } \\
\text { bertambah ketika tanggal dan waktu saat ini } \\
\text { sudah sesuai seperti pada kolom Start. }\end{array}$ \\
\hline TGF02002 & $\begin{array}{l}\text { Aplikasi berjalan sesuai jadwal yang diinputkan pada kolom } \\
\text { End }\end{array}$ & $\begin{array}{l}\text { Muncul tanggal dan waktu sesuai input dari } \\
\text { pengguna pada kolom End di pop up. } \\
\text { Aplikasi langsung bekerja dan akan berhenti } \\
\text { ketika tanggal dan waktu saat ini sudah } \\
\text { sesuai seperti pada kolom End }\end{array}$ \\
\hline TGF02003 & $\begin{array}{l}\text { Aplikasi berjalan sesuai jadwal yang diinputkan pada kolom } \\
\text { Start dan End }\end{array}$ & $\begin{array}{l}\text { Muncul tanggal dan waktu sesuai input dari } \\
\text { pengguna pada kolom Start dan End di pop } \\
\text { up. Aplikasi mulai bekerja dengan } \\
\text { menunjukkan gambar loading bergerak dan } \\
\text { jumlah data bertambah ketika tanggal dan } \\
\text { waktu saat ini sudah sesuai seperti pada } \\
\text { kolom Start. Aplikasi akan berhenti ketika } \\
\text { tanggal dan waktu saat ini sudah sesuai } \\
\text { seperti pada kolom End }\end{array}$ \\
\hline TGF02004 & Aplikasi meminta pengguna untuk menginputkan penjadwalan & $\begin{array}{l}\text { Muncul pop up bahwa pengguna harus } \\
\text { menginputkan waktu tanggal dan waktu pada } \\
\text { kolom Start atau End }\end{array}$ \\
\hline TGF02005 & $\begin{array}{l}\text { Aplikasi memperingatkan pengguna bahwa jadwal pada kolom } \\
\text { Start tidak valid karena tanggal tidak tepat }\end{array}$ & $\begin{array}{l}\text { Muncul pop up bahwa tanggal atau waktu } \\
\text { pada kolom Start tidak valid }\end{array}$ \\
\hline TGF02006 & $\begin{array}{l}\text { Aplikasi memperingatkan pengguna bahwa jadwal pada kolom } \\
\text { Start tidak valid karena waktu tidak tepat }\end{array}$ & $\begin{array}{l}\text { Muncul pop up bahwa tanggal atau waktu } \\
\text { pada kolom Start tidak valid }\end{array}$ \\
\hline TGF02007 & $\begin{array}{l}\text { Aplikasi memperingatkan pengguna bahwa jadwal pada kolom } \\
\text { End tidak valid karena tanggal tidak tepat }\end{array}$ & $\begin{array}{l}\text { Muncul pop up bahwa tanggal atau waktu } \\
\text { pada kolom End tidak valid }\end{array}$ \\
\hline
\end{tabular}




\begin{tabular}{|c|c|c|}
\hline TGF02008 & $\begin{array}{l}\text { Aplikasi memperingatkan pengguna bahwa jadwal pada kolom } \\
\text { End tidak valid karena waktu tidak tepat }\end{array}$ & $\begin{array}{l}\text { Muncul pop up bahwa tanggal atau waktu } \\
\text { pada kolom End tidak valid }\end{array}$ \\
\hline TGF02009 & $\begin{array}{l}\text { Aplikasi memperingatkan pengguna bahwa jadwal pada kolom } \\
\text { Start tidak valid karena tanggal dan waktu yang diinputkan } \\
\text { merupakan tanggal dan waktu sebelum dari saat ini }\end{array}$ & $\begin{array}{l}\text { Muncul pop up bahwa tanggal atau waktu } \\
\text { pada kolom Start tidak boleh sebelum dari } \\
\text { saat ini }\end{array}$ \\
\hline TGF02010 & $\begin{array}{l}\text { Aplikasi memperingatkan pengguna bahwa jadwal pada kolom } \\
\text { End tidak valid karena tanggal dan waktu yang diinputkan } \\
\text { merupakan tanggal dan waktu sebelum dari saat ini }\end{array}$ & $\begin{array}{l}\text { Muncul pop up bahwa tanggal atau waktu } \\
\text { pada kolom End tidak boleh sebelum dari } \\
\text { saat ini }\end{array}$ \\
\hline TGF02011 & $\begin{array}{l}\text { Aplikasi memperingatkan pengguna bahwa jadwal pada kolom } \\
\text { Start harus sebelum jadwal pada kolom End }\end{array}$ & $\begin{array}{l}\text { Muncul pop up bahwa tanggal atau waktu } \\
\text { pada kolom Start harus sebelum dari tanggal } \\
\text { atau waktu pada kolom End }\end{array}$ \\
\hline \multicolumn{3}{|c|}{ Fitur Pengelolaan Xpath } \\
\hline ID & Skenario Test & Expected Results \\
\hline TGF03001 & $\begin{array}{l}\text { Aplikasi melakukan update XPath pada halaman Twitter versi } \\
\text { rilis } 21 \text { April } 2020\end{array}$ & $\begin{array}{l}\text { Tombol update tidak dapat ditekan dan } \\
\text { update XPath tidak dapat dilakukan }\end{array}$ \\
\hline TGF03002 & Aplikasi melakukan restore XPath sesuai default & XPath kembali ke versi rilis 21 April 2020 \\
\hline TGF03003 & $\begin{array}{l}\text { Aplikasi melakukan update XPath pada halaman Twitter } \\
\text { selain versi rilis } 21 \text { April } 2020\end{array}$ & XPath telah mengalami update \\
\hline TGF03004 & $\begin{array}{l}\text { Aplikasi melakukan update XPath pada halaman Twitter } \\
\text { selain versi rilis } 21 \text { April } 2020 \text { dan diinterupsi oleh pengguna }\end{array}$ & $\begin{array}{l}\text { Muncul pop up bahwa XPath gagal } \\
\text { dilakukan update dan XPath kembali ke } \\
\text { versi rilis } 21 \text { April } 2020\end{array}$ \\
\hline TGF03005 & $\begin{array}{l}\text { Aplikasi melakukan update XPath kembali pada halaman } \\
\text { Twitter selain versi rilis } 21 \text { April } 2020 \text { setelah update XPath } \\
\text { sebelumnya diinterupsi oleh pengguna }\end{array}$ & XPath telah mengalami update \\
\hline \multicolumn{3}{|c|}{ Fitur Pengelolaan Database } \\
\hline ID & Skenario Test & Expected Results \\
\hline TGF04001 & Aplikasi mengekspor data yang tersedia pada database & $\begin{array}{l}\text { File TweetGrabberERA.csv terunduh sesuai } \\
\text { data pada database }\end{array}$ \\
\hline TGF04002 & Aplikasi menghapus data pada database & $\begin{array}{l}\text { Database TweetGrabberERA pada } \\
\text { IndexedDB terhapus }\end{array}$ \\
\hline TGF04003 & Aplikasi mengekspor data setelah database dihapus & $\begin{array}{l}\text { File TweetGrabberERA.csv terunduh tanpa } \\
\text { terisi data apapun. }\end{array}$ \\
\hline
\end{tabular}

\subsubsection{Pengujian Validasi Dataset}

Pengujian validasi dataset dilakukan oleh penulis akan dilalui dengan langkah-langkah yang telah disusun ke dalam beberapa skenario. Penulis akan melakukan validasi terhadap file CSV yang disiapkan dari hasil ekspor aplikasi yang berisi 15.000 rekam data. Validasi terhadap file CSV dilakukan dengan menggunakan tool open source CSV Validator GUI 1.2 oleh The National Archives. File CSV Schema pada Gambar 6 yang disusun dalam bahasa skema berbasis teks diperlukan untuk validasi sebagai file yang mendeskripsikan isi data pada file CSV. Ekspektasi dari pengujian ini, diharapkan file CSV mendapatkan respons pass dari validator.

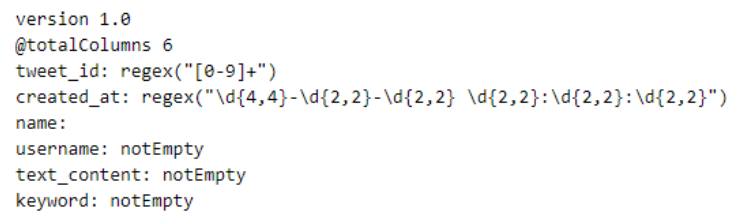

Gambar 6. CSV Schema

Pengujian selanjutnya akan dilakukan dengan cara melakukan pengolahan data dengan dataset ini menggunakan tools Orange 3.24.0 yang merupakan open source machine learning dan visualisasi data. Dari 15.000 rekam data yang ada pada file CSV akan diambil sebanyak 150 sample data secara acak untuk dilakukan analisis sentimen dengan metode VADER (Valence Aware Dictionary and sEntiment Reasoner) melalui fitur yang telah tersedia pada tools Orange. Sebelum dilakukan analisis sentimen, data akan melewati tahap preprocess text. Ada 3 hal yang akan dilakukan pada tahap tersebut yaitu sebagai berikut:

- Transformasi untuk mengubah data pada setiap kata menjadi huruf kecil, menghapus aksen, dan menghapus URL yang tersimpan pada teks. 
- Tokenisasi untuk memecah teks menjadi komponen yang lebih kecil yaitu potonganpotongan kata.

- Penyaringan untuk menghapus kata sambung dan tanda baca termasuk simbol hashtag dan at.

Analisis sentimen yang dihasilkan oleh tools Orange nantinya akan dibandingkan dengan analisis sentimen yang dihasilkan oleh pakar, untuk melihat apakah hasil dari tools dengan pakar memiliki jawaban yang sama atau tidak. Analisis sentimen oleh pakar didapatkan melalui kuesioner dengan kriteria responden yang dicari adalah berstatus sebagai seorang mahasiswa. Sentimen terbanyak dari analisis setiap rekam data yang dinyatakan oleh pakar akan digunakan untuk dibandingkan dengan hasil analisis sentimen dari tool Orange.

Menurut Albert dkk. [7] confusion matrix menggunakan data dalam bentuk matriks yang menyajikan informasi prediksi dan aktual dari suatu sistem klasifikasi yang memiliki data jawaban benar. Dari informasi pada matriks tersebut dapat diperoleh akurasi yaitu nilai seberapa akurat data terklasifikasi dengan benar.

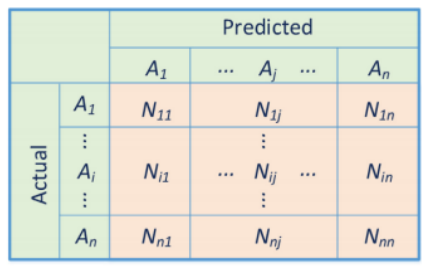

Gambar 7. Confusion matrix untuk multi-class

Pada Gambar 7 menurut Deng dkk. [8] menampilkan bentuk confusion matrix untuk kalsifikasi multi-class $\left(\mathrm{A}_{1}, \mathrm{~A}_{2}\right.$, hingga $\left.\mathrm{A}_{\mathrm{n}}\right)$, dengan keterangan $\mathrm{N}_{\mathrm{ij}}$ sebenarnya merupakan kelas Ai tetapi diprediksi sebagai kelas $\mathrm{A}_{\mathrm{j}}$ sehingga akurasi dirumuskan menjadi Rumus 1 .

$$
\text { Akurasi }=\frac{\sum_{i=1}^{n} N_{i i}}{\sum_{i=1}^{n} \sum_{j=1}^{n} N_{i j}}
$$

Perhitungan akan digunakan sesuai dengan penelitian oleh Deng dkk. (2016) tetapi dalam persentase sehingga ditulis seperti Rumus 2.

$$
\text { Akurasi }=\frac{\sum_{i=1}^{n} N_{i i}}{\sum_{i=1}^{n} \sum_{j=1}^{n} N_{i j}} \times 100 \%
$$

Hasil dari pengujian ini diharapkan dapat menunjukkan bahwa dataset yang didapat dari ekspor data aplikasi bisa digunakan untuk keperluan analisis oleh data scientist salah satunya untuk analisis sentimen.

\section{HASIL DAN PEMBAHASAN}

\subsection{Implementasi Sistem}

\subsubsection{Fitur Grabbing Data}

Grabbing data merupakan fitur utama aplikasi ini. Aplikasi akan bekerja melakukan pengambilan data tweet kiriman pengguna pada halaman web media sosial Twitter. Pengambilan data tweet dilakukan dengan cara menelusuri elemen-elemen pada halaman pencarian Twitter yang sedang dibuka pada browser. Halaman yang dibuka merupakan halaman pencarian Twitter dalam bahasa Inggris yang mengandung keyword yang dimasukkan oleh pengguna.

Halaman web Twitter menggunakan AJaX untuk menampilkan seluruh tweet di halaman web sehingga aplikasi perlu menunggu beberapa waktu hingga tweet ditampilkan sepenuhnya. Ketika halaman web Twitter telah tampil sepenuhnya, aplikasi akan mulai mengambil data sesuai XPath yang telah disimpan pada local storage oleh aplikasi. Dapat dilihat daftar XPath yang digunakan 
oleh aplikasi pada Table VI. Seluruh key pada Tabel 6 memiliki value berupa XPath yang tersimpan pada local storage sesuai halaman web Twitter versi rilis 21 April 2020.

Tabel 6 Daftar Xpath Yang Tersimpan Pada Local Storage

\begin{tabular}{|c|c|}
\hline Key & Value \\
\hline xpathSearchKeyword & //input[@enterkeyhint='search'] \\
\hline xpathNoResults & //div[@data-testid='primaryColumn']/div[1]/div[2]/div[1]/div[1]/div[1]/div[1]/span[1] \\
\hline xpathMain & (//section[@ role='region'])[1]/div[1]/div[1]/div[1] \\
\hline xpathMinorName & $\begin{array}{l}\text { //article[1]/div[1]/div[@data- } \\
\text { testid='tweet']/div[2]/div[1]/div[1]/div[1]/div[1]/div[1]/a[1]/div[1]/div[1] }\end{array}$ \\
\hline xpathMinorUsername & $\begin{array}{l}\text { //article[1]/div[1]/div[@data- } \\
\text { testid='tweet']/div[2]/div[1]/div[1]/div[1]/div[1]/div[1]/a[1]/div[1]/div[2] }\end{array}$ \\
\hline xpathMinorFirstLine & //article[1]/div[1]/div[@data-testid='tweet']/div[2]/div[2]/div[1] \\
\hline xpathMinorSecondLine & //article[1]/div[1]/div[@data-testid='tweet']/div[2]/div[2]/div[2] \\
\hline xpathMinorTweetIdRaw & //article[1]/div[1]/div[@data-testid='tweet']/div[2]/div[1]/div[1]/div[1]/div[1]/a[1] \\
\hline xpathMinorDate & //article[1]/div[1]/div[@data-testid='tweet']/div[2]/div[1]/div[1]/div[1]/div[1]/a[1]/time[1] \\
\hline
\end{tabular}

Masing-masing key pada Tabel 6 dimasukkan ke dalam variabel pada code aplikasi. Inisialisasi nama variabel pada code dibuat sama dengan nama key pada local storage. Variabelvariabel tersebut perlu disusun kembali pada code untuk mendapatkan data yang dibutuhkan untuk disimpan pada database. Penyesuaian susunan variabel-variabel pada code tersebut dijelaskan melalui Tabel 7.

Tabel 7 Daftar Variabel Yang Digunakan Untuk Menampung Xpath

\begin{tabular}{|l|l|}
\hline \multicolumn{1}{|c|}{ Variabel } & \multicolumn{1}{c|}{ Value } \\
\hline contentKeyword & xpathSearchKeyword \\
\hline contentName & xpathMain + "/div[" + tweetLine + "]" + xpathMinorName \\
\hline contentUsername & xpathMain + "/div[" + tweetLine + "]" + xpathMinorUsername \\
\hline contentFirstLine & xpathMain + "/div[" + tweetLine + "]" + xpathMinorFirstLine \\
\hline contentSecondLine & xpathMain + "/div[" + tweetLine + "]" + xpathMinorSecondLine \\
\hline contentTweetIdRaw & xpathMain + "/div[" + tweetLine + "]" + xpathMinorTweetIdRaw \\
\hline contentDate & xpathMain + "/div[" + tweetLine + "]" + xpathMinorDate \\
\hline
\end{tabular}

XPath yang telah disusun akan digunakan untuk mendapatkan elemen dari halaman web Twitter. Salah satu method dari DOM (Document Object Model) yaitu document.evaluate() berfungsi untuk mengevaluasi ekspresi XPath. Hasil pengembalian dari method tersebut dapat memiliki tipe yang bervariasi. Pada kasus ini penulis menggunakan properti singleNodeValue untuk mendapatkan hasil pengembalian dengan tipe elemen node. Method document.evaluate() telah penulis terapkan pada fungsi getElementByXpath() yang dapat dilihat pada Gambar 8 .

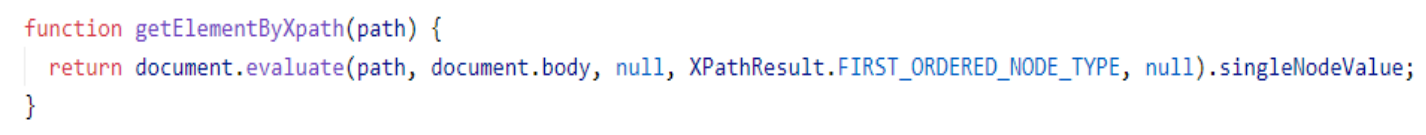

Gambar 8. Penerapan method document.evaluate()

Hasil pengembalian bisa null jika XPath yang dievaluasi tidak ada dalam dokumen HTML. Selanjutnya elemen yang berhasil didapat akan disaring kembali untuk diambil sesuai kebutuhan.

\subsubsection{Fitur Penjadwalan}

Penjadwalan menjadi fitur pilihan pada aplikasi ini. Pengguna dapat menggunakan fitur penjadwalan untuk mengatur kapan aplikasi mulai berjalan maupun berhenti. Fasilitas pada fitur 
ini mengizinkan pengguna untuk dapat mengatur jadwal dengan memasukkan salah satu waktu aplikasi dimulai, waktu aplikasi selesai, atau keduanya sekaligus. Fitur penjadwalan dapat diaktifkan melalui switch pada halaman utama menu pop up oleh pengguna.

Aplikasi akan langsung melakukan grabbing data jika fitur penjadwalan tidak diaktifkan, dan akan berhenti ketika pengguna menekan tombol STOP pada Gambar 4. Jika fitur penjadwalan diaktifkan, maka program akan mulai melakukan grabbing data sesuai jadwal yang telah dimasukkan oleh pengguna.

Pengecekan waktu dilakukan di bagian background aplikasi. Background akan bekerja mengecek datetime setiap detik untuk melihat apakah sudah waktunya bagi aplikasi untuk mulai melakukan grabbing data atau melihat apakah sudah waktunya bagi aplikasi untuk menghentikan aplikasi sesuai datetime penjadwalan yang telah diatur. Tugas pengecekan waktu pada background ini hanya bekerja jika fitur penjadwalan diaktifkan. Jika tidak diaktifkan, maka background tidak perlu melalukan pengecekan waktu.

Tidak lepas dari kerja browser, fitur penjadwalan hanya dapat berjalan jika tab browser yang digunakan untuk mengambil data tetap dibiarkan terbuka. Jika tab browser atau jendela browser ditutup, maka aplikasi termasuk fitur penjadwalan akan berhenti bekerja.

\subsubsection{Fitur Pengelolaan XPath untuk Update XPath}

Fitur update XPath ini berfungsi untuk melakukan update XPath pada aplikasi jika terjadi perubahan pada struktur elemen halaman web Twitter. Tombol ini dapat ditemui pada menu Setting halaman pop up aplikasi. Secara default tombol tidak dapat diklik, tombol hanya bisa diklik apabila aplikasi mendeteksi adanya perubahan pada struktur elemen halaman web Twitter. Untuk dapat mendeteksi hal ini, pengecekan struktur elemen dilakukan oleh aplikasi setiap aplikasi memulai untuk menjalankan tugas grabbing data. Jika jumlah elemen child dari document.body dan struktur elemen masih sesuai dengan XPath yang disimpan pada Tabel 6, maka grabbing data akan berjalan. Jika tidak, maka aplikasi akan menghentikan kerjanya dan mengirim pemberitahuan kepada pengguna untuk melakukan update melalui menu Setting. Hal ini akan memicu tombol update menjadi bisa diklik.

Fitur update XPath akan bekerja secara otomatis dalam melakukan pembaruan ini. Aplikasi akan melakukan scan struktur elemen secara mandiri ke halaman web Twitter yang telah disiapkan. Pengguna tinggal menunggu beberapa saat hingga scan struktur elemen telah selesai dilakukan dan XPath diperbarui. Pada Tabel 8 menunjukkan XPath Absolute yang digunakan untuk melakukan update XPath sesuai halaman web Twitter yang sedang dibuka. XPath tersebut bersifat mutlak ada pada halaman yang telah disiapkan hingga didapatkan elemen yang dicari. Dari elemen tersebut aplikasi akan mengambil parent node hingga menemukan tag body pada halaman tersebut. Tersusunlah XPath baru hasil dari pengaksesan parent node dari elemen tersebut lalu ditampung kembali pada local storage. 
Tabel 8 Daftar XPath Absolute

\begin{tabular}{|c|c|c|}
\hline Variabel & Value & URL Halaman \\
\hline xpathScanNoResults & $/ /{ }^{*}[$ contains(text(),'No results')] & $\begin{array}{l}\text { https://twitter.com/searc } \\
\text { h?q=Tweet\%20Grabber } \\
\% 20 \text { (from\%3Aerindares } \\
\text { ha)\%20until\%3A2020- } \\
01-01\end{array}$ \\
\hline xpathScanSearchKeyword & //input[@placeholder='Search Twitter'] & \multirow{8}{*}{$\begin{array}{l}\text { https://twitter.com/searc } \\
\text { h?\&q=Tweet\%20Grabbe } \\
\text { r\%20(from\%3Aerindares } \\
\text { ha) }\end{array}$} \\
\hline xpathScanName & $\left(/ /{ }^{*}\left[\operatorname{text}()={ }^{\prime}\right.\right.$ Erinda Resha']) $[3]$ & \\
\hline xpathScanTweetIdRaw & //*[contains(@ @ref,'1247305302032052226')] & \\
\hline xpathScanDate & $\begin{array}{l}\text { //@*[contains(.,'2020-04-06T23:28:52.000Z') or } \\
\text { contains(.,'1586215732')][1]/parent::* }\end{array}$ & \\
\hline xpathScanUsername1 & $\begin{array}{l}\left(/ /{ }^{*}\left[\left(\operatorname{contains}(\operatorname{text}(),)^{\prime} @\right) \text { and contains }(\operatorname{text}(),)^{\prime} \text { 'erindaresha')) or }\right.\right. \\
\left(\operatorname{contains}(\operatorname{text}(),)^{\prime} @\right) \text { and *[contains }\left(\operatorname{text}(),{ }^{\prime} \text { erindaresha')])])[3] }\right.\end{array}$ & \\
\hline xpathScanUsername2 & $\begin{array}{l}\left(/ /{ }^{*}\left[\left(\operatorname{contains}(\operatorname{text}(),)^{\prime} @\right) \text { and contains }(\operatorname{text}(),)^{\prime} \text { 'erindaresha')) or }\right.\right. \\
\left(\operatorname{contains}\left(\operatorname{text}(),{ }^{\prime} @\right) \text { and *[contains }\left(\operatorname{text}(),{ }^{\prime} \text { erindaresha')])])[2] }\right.\right.\end{array}$ & \\
\hline xpathScanFirstLine & $\left(/ /{ }^{*}[.=\right.$ 'Tweet Grabber 1'])[1] & \\
\hline xpathScanSecondLine & $\left(/ / *\left[.==\right.\right.$ Tweet Grabber $\left.\left.3^{\prime}\right]\right)[1]$ & \\
\hline
\end{tabular}

3.1.4 Fitur Pengelolaan XPath untuk Mengembalikan XPath ke Bentuk Default

Fitur mengembalikan XPath ke bentuk default digunakan untuk menyimpan kembali XPath pada aplikasi sesuai halaman web Twitter versi rilis 21 April 2020. Tombol ini dapat ditemukan pada menu Setting halaman pop up aplikasi di bawah tombol update. Fitur ini digunakan untuk mengatasi jika ada kegagalan saat melakukan update XPath, sehingga ketika tombol ditekan XPath yang tersimpan pada local storage akan kembali seperti pada Tabel 6.

\subsubsection{Fitur Pengelolaan Database untuk Export Data}

Fitur export data yang terletak pada menu Setting berfungsi agar pengguna dapat mengekspor data yang telah tersimpan di database menjadi file CSV. File tersebut berisi 6 kolom yang terdiri dari tweet_id, created_at, name, username, text_content, dan keyword. Contoh hasil ekspor data dapat dilihat pada Gambar 9. Dengan menggunakan dukungan dari library AlaSQL, mengekspor data dari IndexedDB menjadi lebih mudah hanya dengan menuliskan query saja.

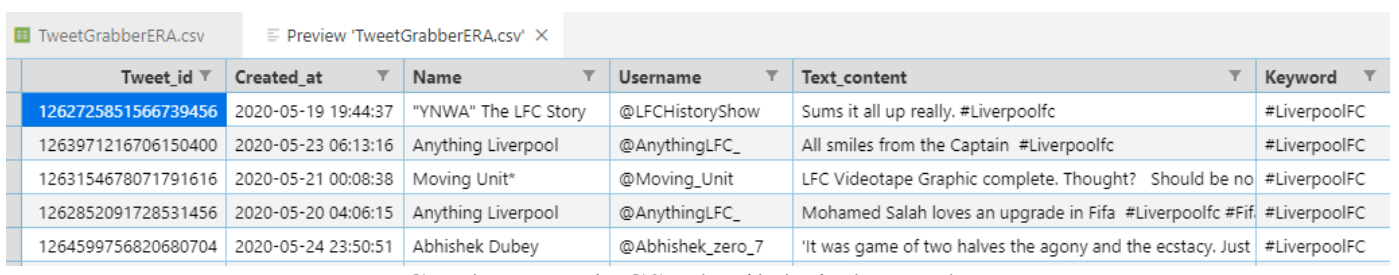

Gambar 9. File CSV hasil dari ekspor data

\subsubsection{Fitur Pengelolaan Database untuk Delete Data}

Menghapus database dapat dilakukan dengan menggunakan fitur delete data. Semua rekam data yang tersimpan pada database akan terhapus. Database penyimpanan dapat diperiksa menggunakan DevTools pada halaman web Twitter, buka tab Application > Storage > IndexedDB $>$ TweetGrabberERA > datas. Jika database telah dihapus maka database TweetGrabberERA tidak akan ditemukan.

\subsection{Analisis Sistem}

\subsubsection{Hasil Pengujian Aplikasi}

Aplikasi TweetGrabberERA telah yang telah selesai dari tahap pembuatan selanjutnya akan diuji untuk melihat apakah aplikasi yang dibangun telah sesuai dengan rancangan kerjanya. Hasil pengujian menunjukkan bahwa aplikasi telah bekerja sesuai rancangan kerja. Pengujian pada aplikasi berjalan seluruhnya sesuai skenario tanpa mengalami adanya kegagalan. Hasil pengujian fitur grabbing data yang terjadi pada aplikasi dengan kondisi menggunakan default XPath dan 
kondisi menggunakan XPath yang telah diperbarui menunjukkan respons yang sama. Hal tersebut menandakan bahwa XPath yang telah diperbarui melalui fitur pengelolaan XPath telah berhasil. Pembaruan XPath yang terjadi tidak mengganggu jalannya fungsi kerja lain di aplikasi. Hasil yang diharapkan pada setiap skenario tes dengan hasil yang sebenarnya terjadi pada fitur grabbing data, fitur penjadwalan, fitur pengelolaan XPath, dan fitur pengelolaan database telah dinilai lulus dan sesuai.

Dapat dilihat dari pengujian ini, aplikasi mampu memberi arahan kepada pengguna untuk menjalankan aplikasi ketika pengguna tidak mengerti apa yang harus dilakukan, ketika pengguna melupakan sesuatu, atau ketika pengguna melakukan kesalahan baik sengaja maupun tidak. Selain itu aplikasi juga sudah bisa menjalankan tugas-tugasnya tanpa mengalami kendala yang berarti. Aplikasi ini berjalan secara fungsional dan tujuannya tetapi tidak disebutkan tingkat efektivitas dan efisiensinya karena penulis tidak melakukan pengujian performa dari kinerja aplikasi.

Pengujian selanjutnya yang akan dilakukan terhadap aplikasi TweetGrabberERA adalah membandingkan fitur atau fasilitas yang telah tersedia dengan aplikasi maupun program yang sama secara fungsionalitasnya. Automatic Crawling Data in Twitter merupakan aplikasi dari penelitian oleh Sembodo dkk. [6], memiliki salah satu fungsi yang sama dengan aplikasi TweetGrabberERA yaitu untuk melakukan pengambilan data pada Twitter. Pada Tabel 9 dapat dilihat hasil perbandingan antara TweetGrabberERA dengan Automatic Crawling Data in Twitter.

Tabel 9 Hasil Perbandingan TweetGrabberERA dengan Automatic Crawling Data in Twitter

\begin{tabular}{|l|l|}
\hline \multicolumn{1}{|c|}{ TweetGrabberERA } & \multicolumn{1}{c|}{ Automatic Crawling Data in Twitter } \\
\hline $\begin{array}{l}\text { Mengimplementasikan XPath } \\
\text { Selector, tidak memerlukan } \\
\text { melakukan pengesahan kredensial }\end{array}$ & $\begin{array}{l}\text { Mengimplementasikan API Twitter, sehingga akan } \\
\text { memerlukan consumer key, consumer access, } \\
\text { access token dan access secret token }\end{array}$ \\
\hline $\begin{array}{l}\text { Metode pencarian berdasarkan } \\
\text { keyword }\end{array}$ & $\begin{array}{l}\text { Metode pencarian berdasarkan } \text { username dan } \\
\text { keyword }\end{array}$ \\
\hline $\begin{array}{l}\text { Pada pengambilan data terakhir, tweet } \\
\text { yang diambil berjumlah } 15.000 \text { dan } \\
\text { dapat terus bertambah. }\end{array}$ & $\begin{array}{l}\text { Jumlah data maksimal yang dapat diambil } \\
\text { berdasarkan } \text { username adalah 200 tweet sedangkan } \\
\text { jika berdasarkan keyword adalah 100 tweet. }\end{array}$ \\
\hline $\begin{array}{l}\text { Penyimpanan data dilakukan pada } \\
\text { IndexedDB }\end{array}$ & $\begin{array}{l}\text { Penyimpanan data dilakukan pada MySQL } \\
\text { Data langsung disimpan pada } \\
\text { database, untuk melihat hasil } \\
\text { pengambilan data harus melalui } \\
\text { DevTools pada browser }\end{array}$ \\
\hline $\begin{array}{l}\text { Data dapat diekspor dengan format } \\
\text { CSV melalui aplikasi }\end{array}$ & $\begin{array}{l}\text { Untuk mengekspor data harus melalui database } \\
\text { ditampilkan kembali pada halaman depan aplikasi }\end{array}$ \\
\hline
\end{tabular}

\subsubsection{Hasil Pengujian Validasi Dataset}

Dataset hasil dari grabbing data akan melakukan 2 tahap pengujian. Pengujian yang pertama yaitu dengan melakukan validasi file format CSV berisi 15.000 rekam data yang dihasilkan oleh aplikasi TweetGrabberERA menggunakan tool open source CSV Validator GUI 1.2 oleh The National Archives dengan skema yang telah disusun pada skenario pengujian. Gambar 10 menunjukkan bahwa 15.000 rekam data pada file CSV telah lolos pengujian. 


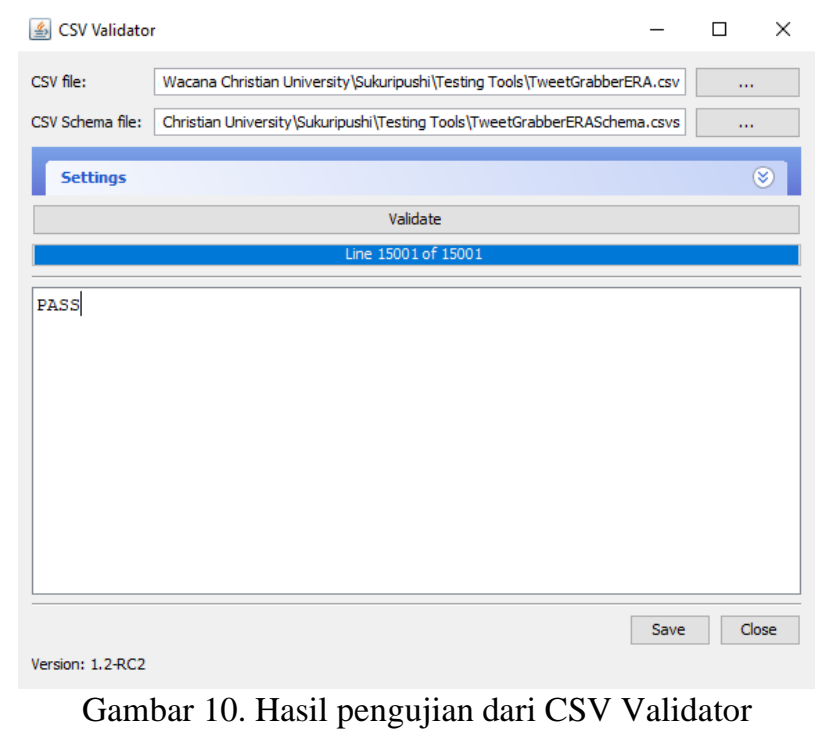

Selanjutnya penulis melakukan pengujian analisis sentimen dari file CSV menggunakan tool open source Orange 3.24.0. Sesuai dengan skenario yang telah dibuat, data yang akan diuji sebanyak 150 rekam sample data diambil secara acak dari file CSV yang telah tersedia melalui tool Orange. Metode VADER yang diterapkan untuk melakukan analisis sentimen pada tool menggunakan kombinasi sentimen lexicon yaitu suatu library yang terdiri dari daftar fitur leksikal seperti kumpulan kata-kata yang dilabeli menurut orientasi sematiknya [9]. Susunan alur kerja kerja widget pada tool Orange dapat dilihat pada Gambar 11.

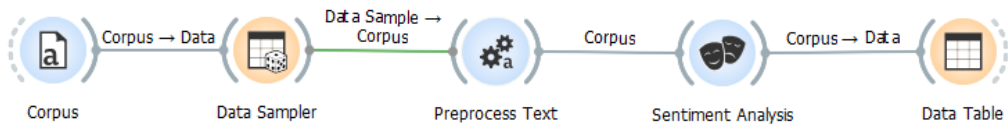

Gambar 1. Alur kerja widget pada tool Orange

Hasil dari metode tersebut melalui tool Orange akan menampilkan skor berdasarkan penilaian kata-kata yang terkumpul yang diinputkan pada kolom positive, negative, neutral, dan compound (total skor). Menurut dokumentasi Orange [10], sentimen direpresentasikan pada kolom compound menunjukkan angka -1 merupakan skor paling negatif, angka 1 merupakan skor paling positif. Hal tersebut membuat penulis memutuskan untuk memberi label pada rekam data menurut skor yang didapat dengan kriteria skor 0 diberi label netral, skor kurang dari 0 diberi label negatif, dan skor lebih dari 0 diberi label positif.

Hasil analisis sentimen oleh tool Orange yang telah diberi label selanjutnya akan dibandingkan dengan hasil analisis sentimen oleh pakar. Penulis telah mengumpulkan 5 responden yang berperan sebagai pakar untuk mengisi kuesioner analisis sentimen. Dari kelima jawaban analisis sentimen oleh pakar, akan diambil sentimen terbanyak pada tiap baris rekam data untuk digunakan sebagai pembanding.

Pada Tabel 10 ditunjukkan confusion matrix hasil perbandingan prediksi sistem oleh tool Orange dengan hasil sebenarnya oleh pakar. Pada prediksi sistem dengan total 150 rekam data memiliki perbedaan 29 dari 70 rekam data dengan label positif yang tidak sesuai, 18 dari 64 rekam data dengan label netral yang tidak sesuai, dan 11 dari 16 rekam data dengan label negatif yang tidak sesuai. Hasil analisis sentimen oleh tool Orange menunjukkan bahwa label positif paling banyak terjadi sedangkan untuk hasil analisis sentimen oleh pakar menunjukkan bahwa label netral paling banyak terjadi. 
Tabel 10 Confusion Matrix

\begin{tabular}{|c|c|c|c|c|c|}
\hline & & \multicolumn{3}{|c|}{ Hasil prediksi sistem (Orange) } & \multirow{2}{*}{ Total } \\
\hline & & Positif & Netral & Negatif & \\
\hline \multirow{3}{*}{$\begin{array}{c}\text { Hasil } \\
\text { sebenarnya } \\
\text { (Pakar) }\end{array}$} & Positif & 41 & 17 & 4 & 62 \\
\hline & Netral & 28 & 46 & 7 & 81 \\
\hline & Negatif & 1 & 1 & 5 & 7 \\
\hline \multicolumn{2}{|c|}{ Total } & 70 & 64 & 16 & 150 \\
\hline
\end{tabular}

Pengujian analisis sentimen terhadap dataset file CSV yang dihasilkan oleh aplikasi TweetGrabberERA berjalan tanpa adanya halangan. Dari perbandingan antara hasil analisis sentimen oleh tool Orange dan pakar ditemukan 92 dari 150 rekam data memiliki hasil analisis sentimen yang sama, sehingga dengan menerapkan Rumus 2 hasil prediksi sistem dapat disebutkan memiliki nilai akurasi sebesar 61,33\%.

\section{KESIMPULAN}

Aplikasi TweetGrabberERA yang dibangun sebagai Chrome Extension untuk data grabber media sosial Twitter telah berhasil mengimplementasikan XPath Selector dengan menerapkan method dari DOM (Document Object Model) yaitu document.evaluate() dan menggunakan properti singleNodeValue, XPath dapat diakses dan menerima hasil pengembalian dengan tipe elemen node. Walaupun menggunakan metode XPath Selector, aplikasi ini mampu beradaptasi pada struktur HTML halaman web Twitter yang berubah-ubah dengan adanya fitur update XPath. Cara kerja update XPath ini dengan memanfaatkan XPath Absolute pada halaman yang telah disiapkan untuk mendapatkan XPath Relative yang baru. XPath Relative inilah yang digunakan oleh aplikasi untuk mendapatkan elemen HTML dari data yang akan diambil.

Pengujian validasi file format CSV yang melibatkan pengecekan skema dataset yang berisi 15.000 rekam data berhasil dilakukan dan dinyatakan lolos. Dilakukan juga analisis sentimen melalui pemberian label sesuai skor yang dihasilkan oleh tool Orange dapat menunjukkan adanya sentimen positif, negatif, dan netral pada setiap rekam sample data yang diambil. Analisis sentimen tersebut dibuktikan validitasnya melalui perbandingan dengan analisis sentimen oleh pakar. Hasil perbandingan tersebut ditemukan bahwa persentase data yang sama antara analisis sentimen oleh tool Orange dengan pakar mencapai $61,33 \%$.

\section{SARAN}

Pada tahap ini penulis ingin menyampaikan beberapa saran untuk dapat menunjang penelitian lebih lanjut:

1. Penelitian yang telah penulis lakukan belum membahas mengenai performa aplikasi, sehingga melakukan perbandingan aplikasi berdasarkan performa tidak dapat dilakukan. Dengan melakukan penelitian mengenai performa, diharapkan aplikasi dapat diukur tingkat efisien dan efektivitasnya.

2. Menambahkan fitur grabbing data berdasarkan username akun Twitter untuk pengembangan aplikasi selanjutnya. 


\section{DAFTAR PUSTAKA}

[1] K. Kellogg, "The 7 Biggest Social Media Sites in 2020," 3 February 2020. [Online]. Available: https://www.searchenginejournal.com/social-media/biggest-social-media-sites/.

[2] Twitter, "Counting characters," tanpa tahun. [Online]. Available: https://developer.twitter.com/en/docs/basics/counting-characters.

[3] Google, "What are extensions?," tanpa tahun. [Online]. Available: https://developers.chrome.com/extensions.

[4] T. Rizaldi and H. Arief, "Perbandingan Metode Web Scraping Menggunakan CSS Selector dan Xpath Selector," TEKNIKA Volume 6 Nomor 1, 2017.

[5] MDN Contributors, "XPath," 24 Nov 2019. [Online]. Available: https://developer.mozilla.org/en-US/docs/Web/XPath.

[6] J. E. Sembodo, E. B. Setiawan and Z. A. Baizal, "Data Crawling Otomatis pada Twitter," Indonesia Symposium on Computing (IndoSC 2016), 2016.

[7] Albert, K. Gunadi and E. Setyati, "Deteksi Helm pada Pengguna Sepeda Motor dengan Metode Convolutional Neural Network," 2014.

[8] X. Deng, Q. Liu, Y. Deng and S. Mahadevan, "An improved method to construct basic probability assignment based on the confusion matrix for classification problem," http://dx.doi.org/10.1016/j.ins.2016.01.033, 2016.

[9] P. Pandey, "Simplifying Sentiment Analysis using VADER in Python (on Social Media Text)," 23 September 2018. [Online]. Available: https://medium.com/analyticsvidhya/simplifying-social-media-sentiment-analysis-using-vader-in-python-f9e6ec6fc52f.

[10] Orange, University of Ljubljana, "Sentiment Analysis," tanpa tahun. [Online]. Available: https://orange.biolab.si/widget-catalog/text-mining/sentimentanalysis/. 